\title{
Szarawara-Kozik's temperature criterion in the context of three-parameter equation for modeling ammonia or methanol decomposition during heterogenous catalysis
}

\author{
Andrzej Mianowski ${ }^{1}$ Tomasz Tiudyga $^{2}$ (D) Jarosław Polański
}

Received: 14 March 2018/Accepted: 25 May 2018/Published online: 11 June 2018

(C) The Author(s) 2018

\begin{abstract}
Szarawara-Kozik's temperature criterion, suggested many years ago, has been reinterpreted as three-parameter fitting equation. We demonstrated interpretation of the chemical reactions of ammonia and methanol catalytic decomposition (to produce syngas and hydrogen) by associating two parameters with the activation energy and the average enthalpy of reaction for the equilibrium conversion degrees. It was proved that the three-parameter equation can be applicable to studying a wide variety of catalytic/enzymatic processes in isothermal conditions.
\end{abstract}

Keywords Ammonia · Methanol · Decomposition · Three-parameter equation · Equilibrium constant

\section{List of symbols}

A

$a, b$

$a_{0}, a_{1}, a_{2}$

$\alpha$

C

E

$\varphi$

$g(\alpha)$

$\Delta_{r} H$

K

$N$

$q$

Tomasz Siudyga

tomasz.siudyga@us.edu.pl

1 Institute for Chemical Processing of Coal, Zamkowa 1, 41-803 Zabrze, Poland

2 Institute of Chemistry, University of Silesia, Szkolna 9, 40-006 Katowice, Poland
Preexponential factor in the Arrhenius equation, $\min ^{-1}$ Constants in $\mathrm{g}(\alpha)$ function

Coefficients in three-parameter Eq. 3

Conversion degree, $0<\alpha \leq 1$,

Constant in Eq. 1

Activation energy of decomposition reaction, $\mathrm{J} \mathrm{mol}^{-1}$

Proportional constant in Eq. 21

Mass integral

Enthalpy of reaction, $\mathrm{J} \mathrm{mol}^{-1}$

Equilibrium constant of reaction

Number of measurements/observations

Heating rate, $\mathrm{K} \mathrm{min}{ }^{-1}$ 


$\begin{array}{ll}Q & \text { Energetic value, } \mathrm{J} \mathrm{mol} \\ R=8.314 \mathrm{~J} \mathrm{~mol}^{-1} \mathrm{~K}^{-1} & \text { Universal gas constant } \\ R^{2} & \text { Determination coefficient in nonlinear regression, } \\ & 0 \leq R^{2} \leq 1 \\ s l & \text { Significance level } \\ T & \text { Temperature of reaction, } \mathrm{K} \\ v & \text { Stoichiometric coefficient } \\ \tau & \text { Time, } \mathrm{s} \\ \tau_{z} & \text { Equivalent time, } \mathrm{g} \mathrm{min} / \mathrm{mol}\end{array}$

\begin{tabular}{ll}
\multicolumn{2}{l}{ Subscripts } \\
av & Average \\
c & Vaporization \\
eq & Equilibrium \\
iso & Isokinetic \\
min & Minimal \\
r & Reaction
\end{tabular}

\section{Introduction}

Kinetic considerations and interpretations of catalytic and non-catalytic reactions have been performed in many publications. Isoconversional methods are most often applied for this purpose [1-7].

Interesting temperature and turbulence criteria for the reactions on heterogeneous catalysts have been published in seventies [8-10]. The above mentioned references, which are available only in Polish, were based on extensive experimental results, described originally in the unpublished $\mathrm{PhD}$ dissertation [11].

The comparison of the temperature and turbulence criterion indicates that the temperature criterion, that is correct for low conversion degree $\alpha$, are of greater importance:

$$
\ln \alpha=C-E / R T, \quad 0<\alpha<0,2
$$

This enables one for the estimation of activation energy.

On the other hand, the constant $C$ has a quite complex origin and depends on the equivalent time of reaction, initial concentrations and grain size of catalyst, but in any case, it does not simply contain the pre-exponential factor $(A)$ in the Arrhenius equation. In this context, in publications [8-11] a discussion is presented on the decomposition of ammonia, methanol, some inorganic salts or solids as well as $\mathrm{SO}_{2}$ oxidation to $\mathrm{SO}_{3}$.

Therein, the temperature criterion 1 was used to analyze the thermal dissociation of a condensed phase assigning a particular form for $\mathrm{C}$ constant in dynamic conditions, that is, for heating rate $\mathrm{q}>0$ [12]: 


$$
\ln \alpha=\ln \left(\frac{0,005 A E}{q R}\right)-E / R T, \quad 0<\alpha<0,2
$$

In this approach it is possible to designate the pre-exponential factor (A) in the Arrhenius equation, which enables the KCE (kinetics compensation effect) analysis.

According to the Ortega considerations [13], Eq. 2 is useful when we consider that for many known functions integral $\mathrm{g}(\alpha)$ for low degrees of conversion of $\mathrm{g}(\alpha)$ takes a value of $g(\alpha)=\mathrm{a} \alpha^{\mathrm{b}}$, where specific values for models a and $\mathrm{b}$ were proposed in work [14]. Thus, comparing the obtained values of the activation energy from Eq. 2 with specific thermokinetic models requires a conversion according to ratio $(E / b)$, where $b=2$ for D-type models, $b=1 / 2$ form A2 and $\mathrm{b}=1 / 3$ for A3.

Finally, we developed [14] a three-parameter thermokinetic equation with the signs consistently compatible $a_{1}, a_{2}$ in comparison to $a_{0}$ :

$$
\ln \alpha=a_{0}-\frac{a_{1}}{T}-a_{2} \ln T \quad \alpha>0
$$

Equation 3 was used in a number of models, whereas this can be concluded more or less by the results presented in [15].

From the formal point of view Eqs. 1 and 2 differ from Eq. 3 by the additional element $\left(-a_{2} \ln \mathrm{T}\right)$.

\section{Aim of work}

The aim of the work is to demonstrate that the three-parameter Eq. 3 is a generalization of temperature relation 1 for isothermal conditions. In such an approach, it is also important how to interpret the Eq. 3 under these conditions, extending the formalism presented in the work [15] for dynamic conditions. Thus, it becomes necessary to interpret the correlation Eq. 4.

$$
a_{1}=\frac{Q}{R}+a_{2} T_{i s o}
$$

Where Q means:

(a) activation energy $E=Q$, for chemical reactions performed far away from equilibrium state DFE (Distance From Equilibrium).

(b) average enthalpy of reaction $\Delta_{r} H / v=Q$ for chemical reactions exhibiting formal and mathematical relationship with equilibrium constant.

\section{Experimental}

The two types of catalytic reactions were used for the analysis: the isothermal decomposition of ammonia and methanol.

The decomposition of ammonia were considered for: 
1. Archival results obtained on $\mathrm{Pt} / \mathrm{Rh}$ catalytic grid in terms of equivalent time 22.5-2256 $\mathrm{min} \mathrm{g} / \mathrm{mol}$, given in [11], and discussed in [8-10].

2. Our study on nanoparticles of active metals on mineral and metallic carriers provided in [16].

On the other hand, the methanol decomposition were analyzed only for archival results $[8-11]$.

\section{Results}

\section{Ammonia Decomposition $\mathrm{NH}_{3} \rightarrow 1 / 2 \mathrm{~N}_{2}+3 / 2 \mathrm{H}_{2}$}

For series experimental data $\mathrm{N}=16$ for equivalent time $\tau_{Z}=22.5-2256$ $\mathrm{g}$ min $\mathrm{mol}^{-1}$ on the $\mathrm{Pt} / \mathrm{Rh}$ catalyst grid (weight of $10.22 \mathrm{~g}$ ), three-parameter Eq. 3 was valid for the determination coefficient $R^{2}=0.9633-0.9984$ (significance level of at least 0.001 ) with a clear trend of increase in $R^{2}$ with increasing equivalent time or otherwise-with a more complete decomposition in a wider temperature range.

Then, the obtained coefficients of Eq. 4 were correlated according to [15], for the positive signs, but rather kinetic than thermodynamic nature was assigned to intercept:

$$
a_{1}-a_{2} T_{i s o}=\frac{E}{R}
$$

Equation 4, which is also another form of $\mathrm{KCE}$, can be used twice:

1. for each individual case $(N=16)$ using the designated isokinetic temperature for the calculation of activation energy $E_{i}$,

2. directly by considering the intercept as an average activation energy $E$.

Fig. 1 illustrates the relationship between the obtained activation energy values and the equivalent time for archival data.

Equation 4 takes a following analytical form:

$$
a_{1}=14290.9+a_{2} T_{i s o}, \text { where } T_{\text {iso }}=885.34 \mathrm{~K}, \quad E=118.8 \mathrm{~kJ} \mathrm{~mol}^{-1}
$$

The occurrence of the maximum, amounting to $E=136.9 \mathrm{~kJ} \mathrm{~mol}^{-1}$ with a minimum values at the level $E \approx 100 \mathrm{~kJ} \mathrm{~mol}^{-1}$ and the average value of $118.8 \mathrm{~kJ} \mathrm{~mol}^{-1}$ is a characteristic feature of the plot shown in Fig. 1. The results of these analyses are in accordance with the temperature criterion resulting from Eq. 1 for $\alpha \leq 0.2$.

For studies using nanocatalysts [16] with a constant flow rate of $2 \mathrm{dm}^{3} \mathrm{~h}^{-1}$ ammonia in isothermal conditions temperature criterion 1 was used for calculation of activation energies as shown in Fig. 2. 


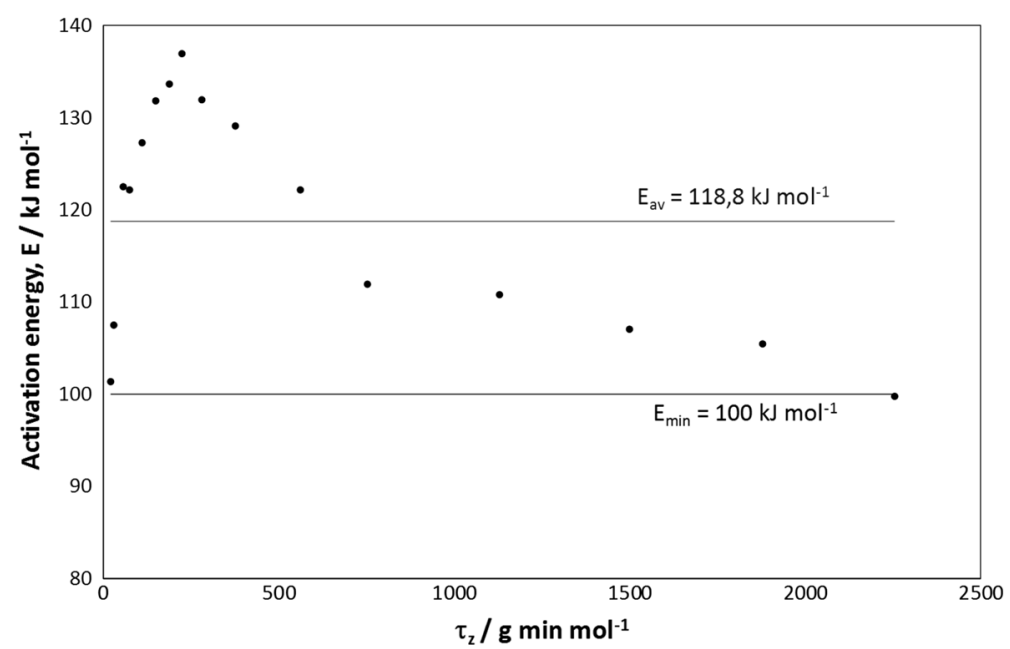

Fig. 1 Relationship between obtained activation energy and equivalent time (for archival data [11])

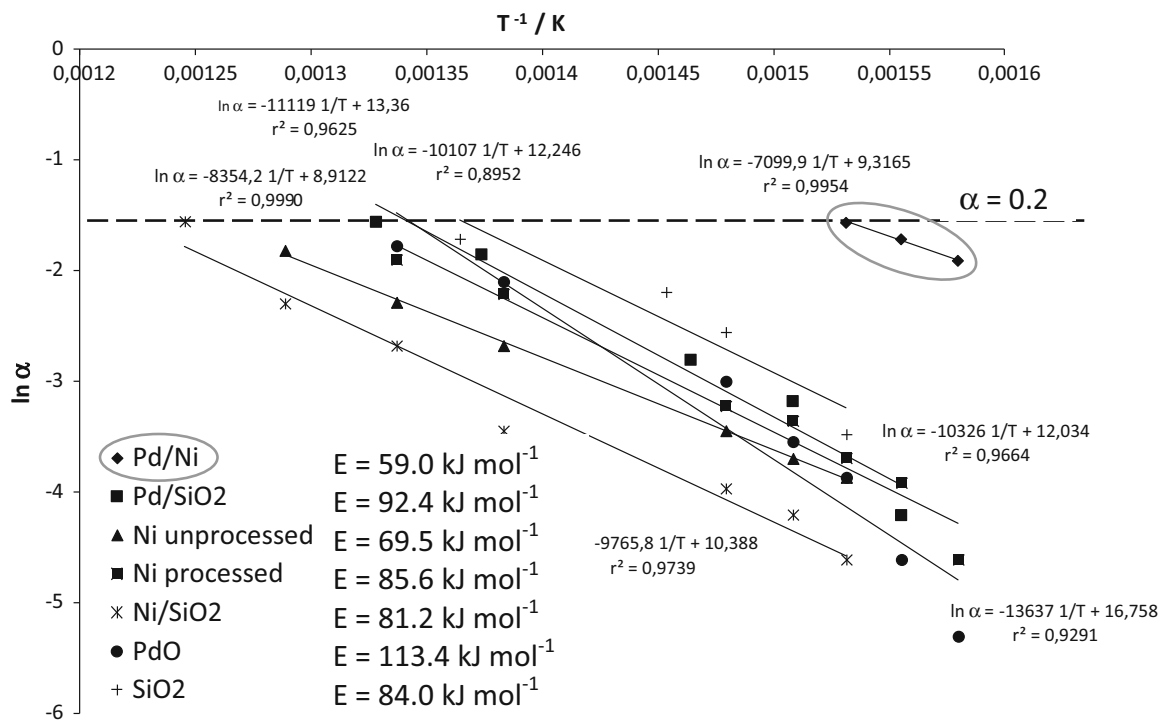

Fig. 2 The analysis of ammonia decomposition on the selected catalysts on the basis of the temperature criterion $1-$ (relation $\alpha$ vs $\mathrm{T}$ in [16], see Fig. S1 in Supplementary Materials)

As previously the coefficients of the three-parameter Eq. 4 were determined with high determination coefficients $R^{2}$ above 0.9555 , while the analytical model takes a form of Eq. 5:

$$
a_{1}=8723,8+a_{2} T_{\text {iso }}, \text { where } T_{\text {iso }}=786.03 \mathrm{~K}, \quad E=72.5 \mathrm{~kJ} \mathrm{~mol}^{-1}
$$


A comparison of these data clearly indicates a very beneficial effect of nanocatalysts, the average activation energy significantly approaching to the enthalpy of this reaction, which also means shortening the DFE.

Individual values are consistent assuming ammonia decomposition on the nickel and ruthenium catalysts for the mechanism consisting of four steps, wherein that for the reactions 2 to 4 according to [17], the activation energies vary in the range $E=144 \rightarrow 109 \mathrm{~kJ} \mathrm{~mol}^{-1}$ (Ni catalyst), and $E=105.8 \rightarrow 67.8 \mathrm{~kJ} \mathrm{~mol}^{-1}$ (Ru catalyst). The results presented in work [16] are very interesting, but obviously there are other works, where valuable results had also been obtained [18].

The appropriate thermodynamic relationship for the equilibrium chemical constant were determined on the basis of Barin's tables [19]:

$$
\ln K_{1}=13.122-5912.35 / \mathrm{T}, \quad 298.15 \mathrm{~K} \leq T \leq 900 \mathrm{~K},
$$

$\Delta_{r} H=49.2 \mathrm{~kJ} \mathrm{~mol}^{-1}$, acc. to [20-22] $\Delta_{r} H=46-49.2 \mathrm{~kJ} \mathrm{~mol}^{-1}$.

The interpretation of Eq. 4 in the form of Eq. 5 complies with the general principle that $E \geq \Delta_{r} H$.

\section{Methanol decomposition $\mathrm{CH}_{3} \mathrm{OH}^{(\mathrm{c}, \mathrm{g})} \rightarrow 2 \mathrm{H}_{2}+\mathrm{CO}$}

The results of studies of this reaction are presented in Ref. [11], mainly in two aspects:

1. for $\mathrm{Zn} / \mathrm{Cr}$ catalyst where equivalent time $\tau_{z}$ amounted to $\tau_{z}=9.74-156 \mathrm{~g} \mathrm{~min} /-$ mol, catalyst weight of $30 \mathrm{~g}$ and $5 \mathrm{~mm}$ grinding (I variant),

2. as in the first variant but for $\tau_{z}=26 \mathrm{~g} \mathrm{~min} \mathrm{~mol}^{-1}$ and variable catalyst grinding of $0.5-1 \mathrm{~mm}, 0.385-0.6 \mathrm{~mm}, 0.385-0.1 \mathrm{~mm},<0.1 \mathrm{~mm}$ (II variant).

In all cases Eq. 3 was found to be correct with the determination coefficients $R^{2}=0.9929-0.9991$ and a significance level of at least 0.0001 .

A value of activation energies $E_{i}$ were determined by applying Eq. 4 in formula 5:

1. for the I variant: $\tau_{z}=v a r$, catalyst grinding $=$ const: $E_{i}=18.7-28.3 \mathrm{~kJ} \mathrm{~mol}^{-1}$, and average activation energy $E$ from analytical form:

$$
a_{1}=3216.86+a_{2} T_{i s o}, \text { where } T_{i s o}=587.43 \mathrm{~K}, \quad E=26.7 \mathrm{~kJ} \mathrm{~mol}^{-1}
$$

2. for the II variant, $\tau_{z}=$ const, catalyst grinding $=$ var: $\quad E_{i}=24.6-39.3$ $\mathrm{kJ} \mathrm{mol}^{-1}$, and average activation energy $E$ from analytical form:

$$
a_{1}=3687.18+a_{2} T_{\text {iso }} \text { where } T_{\text {iso }}=610.82 \mathrm{~K}, \quad E=30.7 \mathrm{~kJ} \mathrm{~mol}^{-1}
$$

After combining both groups of results in Eqs. 9 and 10 one can obtain: 


$$
a_{1}=3234.94+a_{2} T_{\text {iso }} \text { where } T_{\text {iso }}=614.66 \mathrm{~K}, \quad E=26.9 \mathrm{~kJ} \mathrm{~mol}^{-1}
$$

In the case of variant I (variable equivalent time), the $a_{2}$ coefficient is small, taking a maximal value of $a_{2}=16.5$, while for variant II (variable catalyst grinding and fixed equivalent time) it reaches a maximum value of $a_{2}=117$. Fig. 3 illustrates a dependence of activation energy on the equivalent time for variant $\mathrm{I}$.

At the same time, a reduction of three-parameter Eq. 3 to the temperature criterion 1 for a low degree of methanol conversion, $\alpha<0.2$ a high activation energy values are obtained $\mathrm{E}=60-90 \mathrm{~kJ} \mathrm{~mol}^{-1}$ (the II variant).

The appropriate thermodynamic relations for chemical equilibrium constant were determined from the Barin's tables [19] to broaden the obtained results:

- methanol decomposition (to synthesis gas) in the gaseous form:

$$
\begin{aligned}
& \ln K_{2}=28.7024-11652.623 / \mathrm{T}, \text { for } 298.15 \mathrm{~K} \leq \mathrm{T} \leq 1000 \mathrm{~K} \\
& \Delta_{r} H=96.9 \mathrm{~kJ} \mathrm{~mol}^{-1} .
\end{aligned}
$$

- methanol decomposition in the liquid form:

$$
\begin{aligned}
& \ln K_{3}=40.074-15431.710 / \mathrm{T}, \text { for } 298.15 K \leq T \leq 400 \mathrm{~K} \\
& \Delta_{r} H=128.9 \mathrm{~kJ} \mathrm{~mol}^{-1} .
\end{aligned}
$$

The enthalpy difference given by the Eqs. 13 and 12 is the vaporization enthalpy of methanol in a temperature range $298.15-400 \mathrm{~K}$ :

$\Delta_{c} H=31.4 \mathrm{~kJ} \mathrm{~mol}^{-1}\left(\Delta_{c} H=35.3 \mathrm{~kJ} \mathrm{~mol}^{-1}\right.$, when $\left.T_{b}=337.85 \mathrm{~K}[23]\right)$

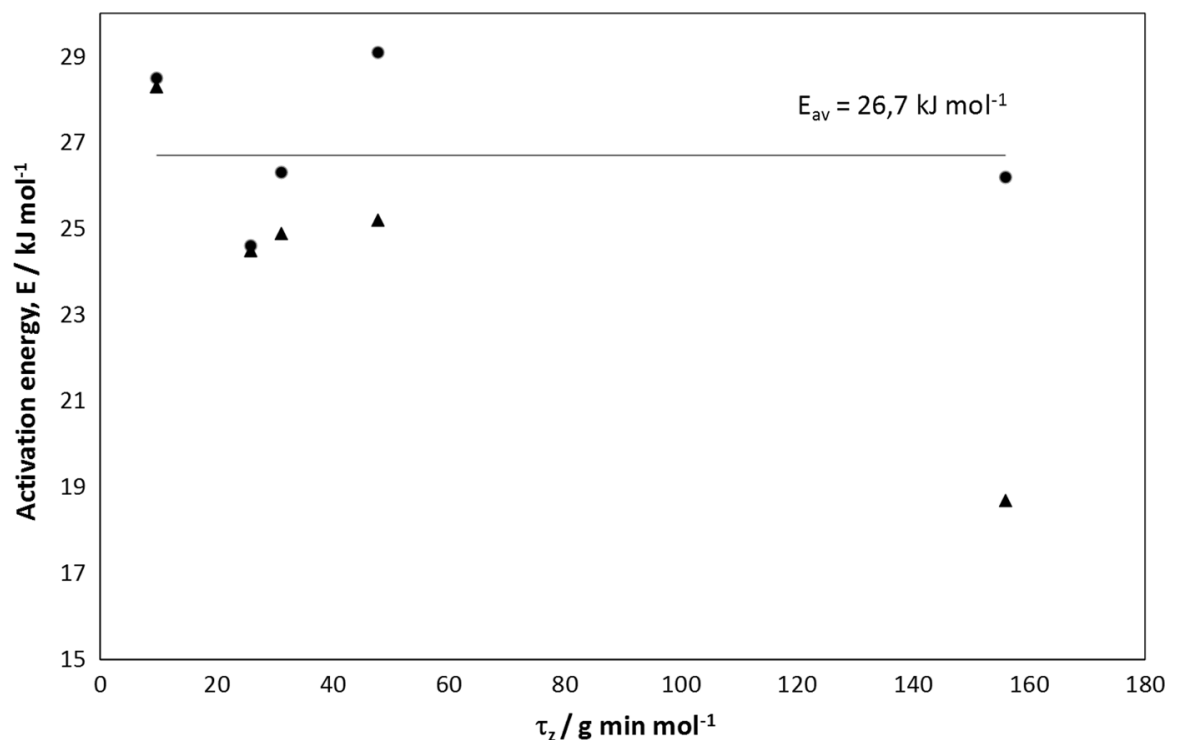

Fig. 3 Dependence of activation energy from the equivalent time for the I variant (triangles-from temperature criterion 1) 
The first observation which arises from the comparison of the activation energy and enthalpy of vaporization is that there are comparable values $\left(E=\Delta_{c} H\right)$, while the additional cases of the high activation energy $\left(E=60-90 \mathrm{~kJ} \mathrm{~mol}^{-1}\right)$ are close in a value to the average enthalpy of the reaction $\left(E \approx \Delta_{c} H\right)$.

This observation will be explained in the next part of work.

\section{Discussion}

\section{Discussion on the results in the aspect of thermodynamic}

The obtained results suggest another interpretation of Eq. 4 which further gives the kinetic form (5). According to the works [15, 24] Eq. 4 appears substantial for the dissociation of solid phase, particularly, in dynamic conditions, where it takes a form:

$$
a_{1}-a_{2} T_{i s o}=\frac{\Delta_{r} H}{v R}
$$

Here the stoichiometric ratio $v$ should be understood as total only for the gaseous products. Practically, in the decomposition of ammonia and methanol the substrates and products are gaseous, except where from ambient temperatures up to the boiling point the substrate (methanol) is in the liquid state.

\section{Ammonia decomposition}

Equilibrium constant for the ammonia decomposition can be expressed by the following equation:

$$
K_{1}=c \frac{\alpha_{e q}^{2}}{1-\alpha_{e q}^{2}}
$$

This can be reduced to the relation of equilibrium conversion degree of ammonia

$$
\alpha_{e q}=\sqrt{\frac{c K_{1}}{1+c K_{1}}}
$$

Here $c=\sqrt{16 / 27}=0.7698$ and $K_{1}$ can be expressed by Eq. 8 .

For a small conversion degree of decomposition $\left(\alpha_{e q}<0.2\right)$ Eq. 15 approximately equals $K_{1} \approx c \alpha_{e q}^{2}$, and from relation: $\ln \alpha_{\text {eq }}$ vs. $1 / T$ (Fig. 4) there was determined $\Delta_{r} H / v=24.36 \mathrm{~kJ} \mathrm{~mol}^{-1}$, and $\Delta_{r} H=48.7 \mathrm{~kJ} \mathrm{~mol}^{-1}(v=2)$, where the designated value is consistent with Eq. 8.

\section{Gaseous methanol decomposition}

Equilibrium constant for the gaseous methanol decomposition can be expressed by the equation: 


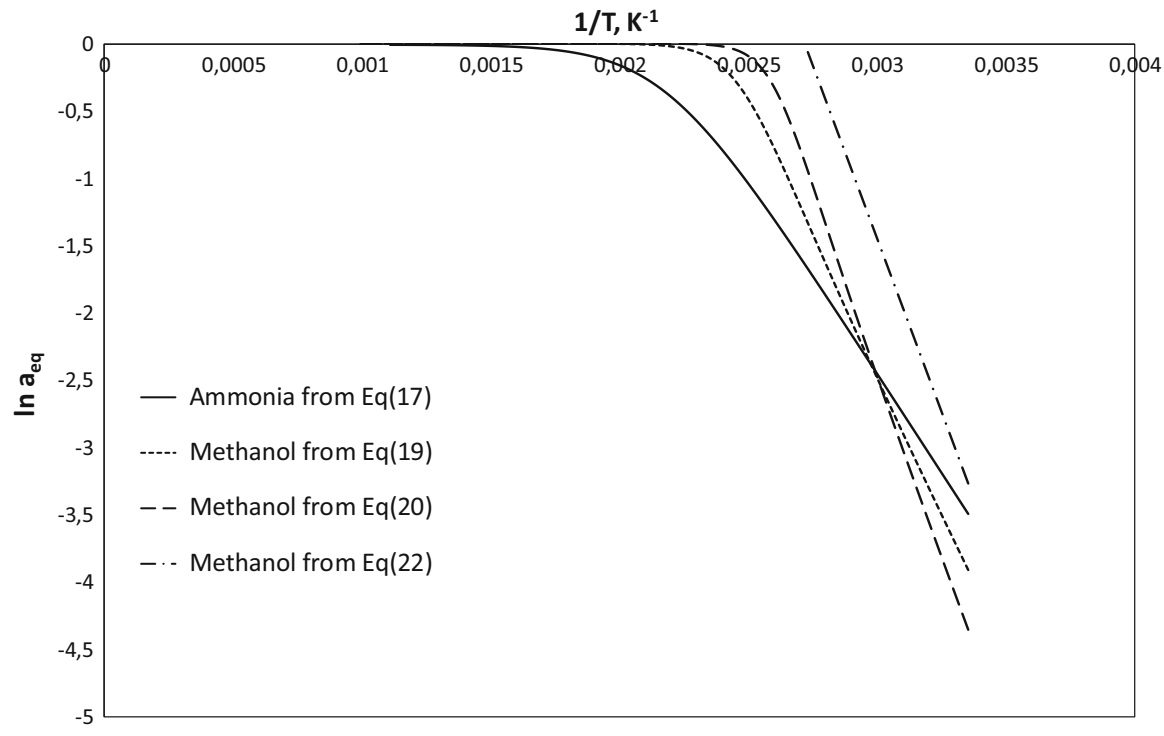

Fig. 4 Relationship $\ln \alpha_{\text {eq }}$ versus $1 / T$ for ammonia and methanol decomposition

$$
K_{2}=\frac{4 \alpha_{e q}^{3}}{\left(1+2 \alpha_{e q}\right)^{2}\left(1-\alpha_{e q}\right)}
$$

This can be transformed by solving equation to dependence of equilibrium conversion degree:

$$
\alpha_{e q}=1 / 2\left(\frac{K_{2}}{1+K_{2}}\right)^{\frac{1}{3}}\left[\left(1+\frac{1}{\sqrt{1+K_{2}}}\right)^{\frac{1}{3}}+\left(1-\frac{1}{\sqrt{1+K_{2}}}\right)^{\frac{1}{3}}\right]
$$

Here $K_{2}$ is expressed by Eq. 12 .

For small conversion degree of decomposition $\left(\alpha_{e q}<0.2\right)$ relation 18 is regulated with regard to the equilibrium value $K_{2} \propto \alpha_{e q}^{3}$, and from relation: $\ln \alpha_{e q}$ vs $1 / T$ (Fig. 4) there was determined $\Delta_{r} H / v=34.19 \mathrm{~kJ} \mathrm{~mol}^{-1}$, and $\Delta_{r} H=102.6 \mathrm{~kJ} \mathrm{~mol}^{-1}(v=3)$ and the designated value is consistent with Eq. 12.

\section{Liquid methanol decomposition}

Although methanol under atmospheric pressure and at temperatures below $T_{\mathrm{b}}=337.85 \mathrm{~K}$ [23] is in liquid form, the discussion can be carried out for two cases.

In a first, we assume the validity of Eq. 18 except that it contains a constant thermodynamic constant $K_{3}$ expressed by Eq. 13: 


$$
\alpha_{e q}=1 / 2\left(\frac{K_{3}}{1+K_{3}}\right)^{\frac{1}{3}}\left[\left(1+\frac{1}{\sqrt{1+K_{3}}}\right)^{\frac{1}{3}}+\left(1-\frac{1}{\sqrt{1+K_{3}}}\right)^{\frac{1}{3}}\right]
$$

Equation 19 assumes that despite the existence of the liquid phase, there are three gas components in its surrounding: $\mathrm{CH}_{3} \mathrm{OH}, \mathrm{CO} \mathrm{i} \mathrm{H}_{2}$.

According to procedure describe above (Fig. 4) there was determined $\Delta_{r} H / v=44.89 \mathrm{~kJ} \mathrm{~mol}^{-1}$, and $\Delta_{r} H=134.7 \mathrm{~kJ} \mathrm{~mol}^{-1}$ for the $v=3$. This value is acceptable in comparison to the value specified in the supplement to Eq. 13.

For the second case of the low temperature decomposition of methanol in the liquid phase (298.15-400 K), a model described in work [15] was used, assuming that the chemical equilibrium constant refers only to gaseous products $\left(\mathrm{CO}\right.$ and $\left.\mathrm{H}_{2}\right)$, and in this case $v=3$ :

Thus

$$
K_{3}=\varphi \alpha_{e q}^{v} \quad \text { where } \quad \varphi=0.1481, \quad \text { and } v=3
$$

Finally:

$$
\alpha_{e q}=1,89\left(K_{3}\right)^{1 / 3}
$$

Here $K_{3}$ expresses relation (13) in the range: $298.15 \mathrm{~K} \leq T \leq 337.85 \mathrm{~K}$.

In the same way (Fig. 4) $\Delta_{r} H / v=42.77 \mathrm{kJmol}^{-1}$, and $\Delta_{r} H=128.3 \mathrm{kJmol}^{-1}$ was calculated, and this value was in accordance with the supplement to the Eq. 13.

The differences indicate the enthalpy of evaporation enthalpy in the range of: $\Delta_{c} H=25.7-32.1 \mathrm{~kJ} \mathrm{~mol}^{-1}$ (in the previous case $\Delta_{c} H=31.4 \mathrm{~kJ} \mathrm{~mol}^{-1}$ ).

In relation to the received values of activation energy, it can be assumed that in the catalytic process activation energy is minimal and similar to evaporation enthalpy $\mathrm{E}=\Delta_{c} H$ and these values are approx. $30 \mathrm{~kJ} \mathrm{~mol}^{-1}$.

The higher activation energies, approaching the average enthalpy of reaction $E=60-90 \mathrm{~kJ} \mathrm{~mol}^{-1}$ are the result of two effects:

(a) according to the authors [10], this is a typical $\mathrm{KCE}$,

(b) according to these considerations, poorly prepared catalyst with low activity is expressed in increased activation energy, at the level of enthalpy of decomposition, according to a relation for the endothermic processes $E \rightarrow \Delta_{r} H$.

It should be appreciated that thermodynamic considerations provided here relate to decomposition of methanol to synthesis gas, and in this regard there are many other possibilities, such as dehydration (DME), dehydrogenation or formation of esters of formic acid etc. [25]. 


\section{Conclusion}

1. For the experimental data of decomposition type reactions under isothermal conditions three-parameter Eq. 3 can make wider the understanding of Szarawara-Kozik's temperature criterion 1. We proposed here other interpretation of the coefficients in Eq. 3 for these conditions, by determining the activation energy.

2. Criteria used for the obtained results of catalytic decomposition of ammonia indicate a considerable more efficient activity of nanocatalysts [16] in relation to the earlier studies [11] and the DFE. The numerical scale DFE can be determined by the average values: $\Delta_{r} H=49.2 \mathrm{~kJ} \mathrm{~mol}^{-1}$, activation energy for data from [11] $E=118.8 \mathrm{~kJ} \mathrm{~mol}^{-1}$ and on nanocatalysts [16] $E=72.5 \mathrm{~kJ} \mathrm{~mol}^{-1}$.

3. In the case of methanol decomposition averaged activation energy is at the level of evaporation enthalpy of methanol $E=\Delta_{c} H$, and these values are approx. $30 \mathrm{~kJ} \mathrm{~mol}^{-1}$. It is interesting that reaction enthalpy was determined by two routes of thermodynamic analysis and they differing by evaporation enthalpy of methanol, ie. $\Delta_{r} H=96.9 \mathrm{~kJ} \mathrm{~mol}^{-1}$ for the gaseous substrates and $\Delta_{r}$ $H=128.3 \mathrm{~kJ} \mathrm{~mol}^{-1}$ for the liquid methanol. This result was confirmed by the simplification introduced by adapting thermodynamic equations in a similar manner to the temperature criterion inserting the equilibrium conversion degree, instead of experimental conversion degree even for $\alpha_{e q}<0.2$.

Acknowledgements We would like to thank prof. J. Szarawara for many years of cooperation and inspiration

Open Access This article is distributed under the terms of the Creative Commons Attribution 4.0 International License (http://creativecommons.org/licenses/by/4.0/), which permits unrestricted use, distribution, and reproduction in any medium, provided you give appropriate credit to the original author(s) and the source, provide a link to the Creative Commons license, and indicate if changes were made.

\section{References}

1. Brown ME, Maciejewski M, Vyazovkin S, Nomen R, Sempere J, Burnham A, Opfermann J, Strey R, Anderson HL, Kemmler A, Keuleers R, Janssens J, Desseyn HO, Li C-R, Tang TB, Roduit B, Malek J, Mitsuhashi T (2000) Computational aspects of kinetic analysis: part A: the ICTAC kinetics projectdata, methods and results. Thermochim Acta 355:125-143

2. Maciejewski M (2000) Computational aspects of kinetic analysis: Part B. The decomposition kinetics of calcium carbonate revisited, ore some tips on survival in the kinetic minefield. Thermochim Acta 355:145-154

3. Vyazovkin S (2000) Computational aspects of kinetic analysis: Part C. The light at the end of the tunnel. Thermochim Acta 355:155-163

4. Burnham AK (2000) Computational aspects of kinetic analysis: Part D. The ICTAC kinetics project-multi-thermal-history model-fitting methods and their relation to isoconversional methods. Thermochim Acta 355:165-170 
5. Roduit B (2000) Computational aspects of kinetic analysis: Part E: The ICTAC kinetics project numerical techniques and kinetics of solid state processes. methods. Thermochim Acta 355:171-180

6. Vyazovkin S, Burnham AK, Criado JM, Pérez-Maqueda LA, Popescu C, Sbirrazzuoli N (2011) ICTAC Kinetics Committee recommendations for performing kinetic computations on thermal analysis data. Thermochim Acta 520:1-19

7. Vyazovkin S, Chrissafis K, di Lorenzo ML, Koga N, Pijolat M, Roduit B, Sbirrazzuoli N, Suñol JJ (2014) ICTAC Kinetics Committee recommendations for collecting experimental thermal analysis data for kinetic computations. Thermochim Acta 590:1-23

8. Szarawara J, Cz Kozik (1973) The issue of area of catalytic processes (Zagadnienie obszaru procesów kontaktowych). Chem Stosow 17:279-294 (in Polish)

9. Szarawara J, Cz Kozik (1973) Attempt at the potential interpretation of chemical kinetics equations (Próba potencjałowej interpretacji równań kinetyki chemicznej). Chem Stosow 17:295-3014 (in Polish)

10. Szarawara J, Cz Kozik (1976) Application of a new method for studies on the area of selected heterogeneous processes (Zastosowanie nowej metody badania obszaru do wybranych procesów heterogenicznych). Chem Stosow 20:45-69 (in Polish)

11. Kozik Cz (1973) Studies on the area of heterogeneous processes (Studia nad obszarem procesów heterogenicznych). PhD thesis, Silesian University of Technology, Faculty Chemistry (in Polish)

12. Mianowski A, Radko T (1994) The possibility of identification of activation energy by means of the temperature criterion. Thermochim Acta 247:389-405

13. Ortega A (1996) The incorrectness of the temperature criterion. Thermochim Acta 276:189-198

14. Mianowski A (2000) Thermal dissociation in dynamic conditions by modeling thermogravimetric curves using the logarithm of conversion degree. J Therm Anal Cal 59:747-762

15. Mianowski A, Siudyga T (2012) Analysis of relative rate of reaction/process. J Therm Anal Cal 109:751-762

16. Polanski J, Bartczak P, Ambrożkiewicz W, Sitko R, Siudyga T, Mianowski A, Szade J, Balin K, Lelątko J (2015) Ni-supprted Pd nanoparticles with Ca promoter: a new catalyst for low-temperature ammonia cracking. PLoS ONE. https://doi.org/10.1371/journal.pone.0136805

17. Takahashi A, Fujitani $T$ (2016) Kinetic analysis of decomposition of ammonia over nickel and ruthenium catalysts. J Chem Eng Jpn 49:22-28

18. Guo J, Chen Z, Wu A, Chang F, Wang P, Hu D, Wu G, Xiong Z, Yu P, Chen P (2015) Electronic promoter of reaction species? The role of $\mathrm{LiNH}_{2}$ on $\mathrm{Ru}$ in catalyzing $\mathrm{NH}_{3}$ decomposition. Chem Commun 51:15161-15164

19. Barin I (1989) Thermochemical data of pure substances, vol 1. VCH Verlagsgesellschaft, Weinheim

20. Klerke A, Christensen CH, Nørskov JK, Vegge T (2008) Ammonia for hydrogen storage: challenges and opportunities. J Mater Chem 18:2304-2310

21. Atsumi R, Noda R, Takagi H, Vecchione L, di Carlo A, del Prete Z, Kuramoto K (2014) Ammonia decomposition activity over $\mathrm{Ni} / \mathrm{SiO}_{2}$ catalysts with different pore diameters. Int J Hydrogen Energy 39:13954-13961

22. Okura K, Okanishi T, Muroyama H, Matsui T, Eguchi K (2015) Promotion effect of rare-earth elements on the catalytic decomposition of ammonia over $\mathrm{Ni} / \mathrm{Al}_{2} \mathrm{O}_{3}$ catalyst. Appl Catal A 505:77-85

23. Knovel Critical Tables (2nd edn). https://app.knovel.com/web/

24. Mianowski A, Urbańczyk W (2016) Thermal dissociation in terms of second law of chemical thermodynamics. J Therm Anal Cal 126:863-870

25. Vedyagin A, Kotolevich Y, Tsyrul'nikov P, Khramov E, Nizovskii A (2016) Methanol dehydrogenation over $\mathrm{Cu} / \mathrm{SiO}_{2}$ catalysts. Int J Nanotechnol 13:183-197 